\title{
BMJ Global Health How context affects implementation of the Primary Health Care approach: an analysis of what happened to primary health centres in India
}

\author{
Sudha Ramani, ${ }^{\oplus 1}$ Muthusamy Sivakami, ${ }^{2}$ Lucy Gilson ${ }^{3,4}$
}

To cite: Ramani S, Sivakami M, Gilson L. How context affects implementation of the Primary Health Care approach: an analysis of what happened to primary health centres in India. BMJ Glob Health 2019;3:e001381. doi:10.1136/ bmjgh-2018-001381

Handling editor Seye Abimbola

- Additional material is published online only. To view please visit the journal online (http://dx.doi.org/10.1136/ bmjgh-2018-001381).

Received 26 December 2018 Revised 27 February 2019 Accepted 16 March 2019

Check for updates

(C) Author(s) (or their employer(s)) 2019. Re-use permitted under CC BY-NC. No commercial re-use. See rights and permissions. Published by BMJ.

${ }^{1}$ Tata Institute of Social Sciences, Mumbai, India ${ }^{2}$ School of Health Systems Studies, Tata Institute of Social Sciences, Mumbai, India ${ }^{3}$ University of Cape Town, Cape Town, South Africa

${ }^{4}$ London School of Hygiene and Tropical Medicine, London, UK

Correspondence to

Sudha Ramani;

sudha_ramani@yahoo.com

\section{ABSTRACT}

Introduction In this paper, we elucidate challenges posed by contexts to the implementation of the Primary Health Care (PHC) approach, using the example of primary health centres (rural peripheral health units) in India. We first present a historical review of 'written' policies in India - to understand macro contextual influences on primary health centres. Then we highlight micro level issues at primary health centres using a contemporary case study.

Methods To elucidate macro level factors, we reviewed seminal policy documents in India and some supporting literature. To examine the micro context, we worked with empirical qualitative data from a rural district in Maharashtra - collected through 12 community focus group discussions, 12 patient interviews and 34 interviews with health system staff. We interpret these findings using a combination of top-down and bottom-up lenses of the policy process.

Results Primary health centres were originally envisaged as 'social models' of service delivery; front-line institutions that delivered integrated care close to people's homes. However, macro issues of chronic underfunding and verticalisation have resulted in health centres with poor infrastructure, that mainly deliver vertical programmes. At micro levels, service provision at primary health centres is affected by doctors' disinterest in primary care roles and an institutional context that promotes risk-averseness and disregard of outpatient care. Primary health centres do not meet community expectations in terms of services, drugs and attention provided; and hence, private practitioners are preferred. Thus, primary health centres today, despite having the structure of a primary-level care unit, no longer embody PHC ideals. Conclusions This paper highlights some contextual complexities of implementing PHC — considering macro (pertaining to ideologies and fiscal priorities) and micro (pertaining to everyday behaviours and practices of actors) level issues. As we recommit to Alma-Ata, we must be cautious of the ceremonial adoption of interventions, that look like PHC — but cannot deliver on its ideals.

\section{BACKGROUND}

Global rhetoric on health has recently showed a renewed interest in the values and practices of comprehensive Primary Health Care (PHC). The adoption of the Sustainable

\section{Key questions}

What is already known?

- Experience since the Alma-Ata declaration has shown that implementing the espoused vision of Primary Health Care (PHC) is not straightforward despite global commitment.

What are the new findings?

- This study highlights some of the challenges posed by contexts to the implementation of the PHC approach through the example of primary health centres in India.

- Primary health centres were originally envisaged as 'social models' of service delivery; frontline services close to the homes of people, that consider people's needs, integrate preventive and curative care and link to specialty care when required. But historical macro and micro contextual issues have led to primary health centres that only look like a PHC intervention, but in reality, are far removed from its philosophy.

What do the new findings imply?

- Contextual constraints can result in interventions (like the primary health centres we studied) that merely look like PHC; but do not embody its spirit.

- Macro (pertaining to ideologies and fiscal choices) as well as micro (pertaining to norms and day-to-day behaviours of actors) contexts can pose challenges to the implementation of the PHC approach; hence, constraints at both levels need to be addressed.

Development Goal of 'healthy lives' and 'wellbeing for all' marks a change towards more holistic considerations of health; in line with the sociopolitical ideas of PHC heralded 40 years ago at the Alma-Ata conference. ${ }^{12}$ Some of these ideas have been reaffirmed recently in global forums. ${ }^{34}$ However, there is an urgent need for these ideas on PHC to take roots within country contexts-for past experience has shown that implementation of $\mathrm{PHC}$ is not straightforward. At a macro level, a whole range of factors in a country's health system 


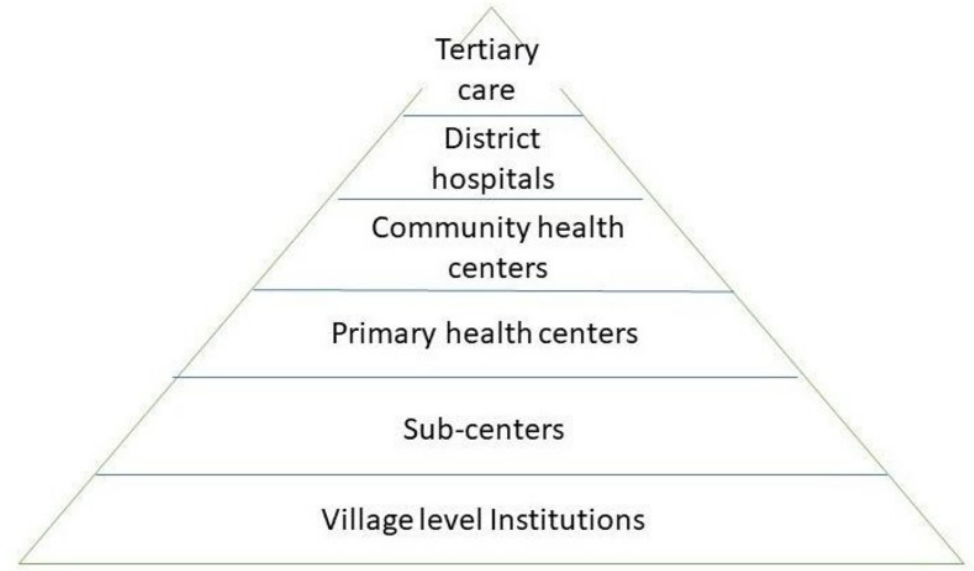

\begin{abstract}
In the rural public health system, primary health centers cater to a population of 30,000 (20,000 in tribal areas), and are envisaged as centers for "integrated curative and preventive health care". These centers are the first contact point between a medical doctor and the community in the public health system. A primary health center is to have 13-21 staff, depending on its outpatient load; at least one Allopathic doctor (who is the Medical Officer in Charge) and several support staff.

As on 31.3.2017 there were 1, 56,231 sub-centres ; 25,650 primary health centres; 5,624 community health centres ; 1108 sub-divisional hospitals and 779 districts hospitals in the country
\end{abstract}

Source: Government of India, Ministry of Health and Family Welfare, Bulletin of Rural Health Statistics 2016-17 (* Variation among states in the exact structure of the tiered system exists)

Figure 1 Rural public health system in India.

context-competing ideologies to the PHC approach (global and country-specific), fiscal priorities and development aid mechanisms that favour vertical programsalong with broader sociopolitical and epidemiological factors-influence the uptake of PHC interventions. ${ }^{5-7}$ Further, these macro issues interact with the 'everyday politics' of the health system ${ }^{8}$ - more specifically, frontline actors' values, past experiences and expectations. ${ }^{9} 10$ All this together influences what happens to PHC on the ground.

We elucidate some challenges posed by contexts to the implementation of PHC using the example of primary health centres in India, a rural peripheral health unit within the public health system (figure 1). These centres were originally visualised in the 1940 s as a 'social model' of health service delivery-frontline services close to the homes of people, that consider people's needs, integrate preventive and curative care and link to specialty care as needed. ${ }^{11}$ The Alma-Ata declaration gave impetus to the expansion of these centres within the country. ${ }^{12}$ However, today's primary health centres are a far cry from what was envisaged originally. These centres are fraught with several infrastructural weaknesses, ${ }^{13-15}$ no longer serve as 'first access institutes' for the community-who rely mainly on local private practitioners ${ }^{16} 17$ and deliver barely $15 \%$ of primary-level services. ${ }^{18}$

In this paper, we analyse what happened to primary health centres in India. First, we present a brief historical review of 'written' policy in India-to understand macro level policy choices-and some of the drivers of these choices-that have shaped primary health centres (the 'macro context'). Then, we use a contemporary case study of primary health centres from one rural area-to delineate some of the ground-level issues at these centres (the 'micro context') - focussing on the norms, practices and expectations of the community and providers at primary health centres. Together, an account of these contexts illustrates some of the complexities in implementing PHC.

\section{METHODS}

Policy implementation processes have been recognised as being shaped by complex interactions between actors, processes and contexts. ${ }^{1920}$ Multiple notions of 'context' exist in literature. Context has been considered as factors beyond the health sector ${ }^{21}$; as having distinct dimensions-situational, structural, cultural and external ${ }^{22}$; and as a source of 'power' that underpins policy-makers choices. $^{23}$ In this study, context mainly refers to factorsat macro levels and micro levels of the health systemthat have influenced primary health centres.

\section{Examining macro contexts}

By macro contexts, we refer to ideologies and fiscal choices (mainly national, but these reverberate with global issues) that have shaped primary health centres in India. We focus on factors that contributed to the originally envisaged model of primary health centres-and subsequent policy choices-influenced by competing ideologies and fiscal priorities-that attenuated this model.

To examine macro contexts, we conducted a historical literature review of 13 national-level policy documents (online supplementary table 1), 5-year national economic plans since independence in 1947 and some supporting literature on the development of Indian health policies (The account of the macro context of primary health 
centres presented in this paper has been derived from a literature review of key policy documents in India, supported by global literature and research on history of public health in India. Some of this narrative has been derived from a larger discourse analysis of Indian policy documents to trace the history of primary health centres and their policy content in India. This analysis focused on ideational contexts that shaped and framed policies in particular ways, rather than others. This larger discourse analysis is not a part of this paper.). The policy documents we examined were not treated as 'self-evident' but as products of broader sociocultural thinking, that endorsed certain ideologies and provided explanations for recommended actions. ${ }^{24}$ Some of these explanations have been presented through illustrative policy quotes (table 1). The Indian authors used their familiarity with the history of Indian health policy to generate an initial list of documents for the review; and this list was vetted by three national experts—one from academia, one ex-policy-maker and one civil society member. These experts also offered suggestions on a summarised narrative. While the focus of the review was on national policies, we drew on some global documents suggested by the experts; and ones mentioned in the Indian policies explicitly. We have presented the review as a historical narrative.

In addition to the national macro context, we briefly reviewed the history of health development in Maharashtra (box 1) - the state where we conducted our case study. This is because, in India, health is a shared responsibility between the federal and state governments; while national policies set goals and fund priority programmes, states fund a major portion of other health activities. ${ }^{25}$ Hence, the state context-overall development status, health priorities and administrative structures-also influences PHC on the ground.

\section{Examining the micro context}

Micro-level contexts, in our study, encompass local actors' values, expectations and practices. By actors, we refer to both community and health system actors. Frontline workers use their discretion to understand, cope and fit a policy idea into their routine behaviours (termed as 'practices'); and it is these practices of frontline workers that the community ultimately experiences as policy. ${ }^{1026}$ This, in turn, affects community expectations from primary health centres and their utilisation. In other words, how local actors interact with a policy idea can be considered as the 'pragmatic context' of policy implementation. ${ }^{9}$

For examining micro contexts, we collected empirical data from a rural area in Maharashtra, that had a mix of primary health centres with good and poor infrastructure-as per national quality standards. ${ }^{27}$ We interacted with both health system staff and the community. Twelve Focus Group Discussions (FGD) were held in the catchment area of seven primary health centres with three only women's groups, one men's group and eight mixed groups (We had some concerns about having only mixed group FGDs; and hence, we conducted a few FGDs separated by gender. But mixed groups in this setting seemed to work as well.) With the community, we discussed generic health seeking notions; and interactions and expectations pertaining to primary health centres. We interviewed 12 patients from three primary health centres to understand why they had chosen to access these. We also conducted In Depth Interviews with health system actors-administrators, doctors, nurses and other support staff at primary health centres-to understand their experiences and expectations (15 doctors, 10 nurses, 5 support staff and 4 senior level staff). The above data were collected by the first author, with assistance from the Centre for Social Medicine, Pravara Institute of Medical Sciences (Four interns helped with data collection, but the first author was a part of all interviews and 10 FGDs. The interns did two FGDs independently).

Data were collected in local language between April and September 2018 - in four iterations-with data analysis happening simultaneously. All recorded FGDs and interviews were transcribed and translated to English. Transcripts were coded inductively through an iterative process to bring out key challenges in the micro context. ${ }^{28}{ }^{29}$ In analysing the data, we followed the three steps described by Miles and Huberman ${ }^{28}$ : (1) Data reduction-in which codes were affixed to blocks of texts; some themes were based on the tools, but many concepts emerged from the data (2) Data display-data were further condensed systematically in three categories: doctors, support staff and the community (3) Drawing conclusions-here, we examined condensed data across all categories to draw inferences on the 'micro context'. NVivo V.12 was used to aid the coding process. The first author led the analysis, but preliminary summaries were shared with the others. During the last iteration of data collection, these summaries were shared with two doctors and with the community during the last two FGDs for validation.

\section{Interpreting the macro and micro contexts together}

We examined two levels of context-macro and microsince dismissing either of these would paint a partial picture: examining only the macro issues would discount local actor values and practices; and examining only the micro issues would ignore the broader policy context. This type of multilevel approach to studying context has been used previously-though studies have mostly looked at three contextual levels-macro, meso and micro. ${ }^{30}$ We looked at only two levels as the boundaries between the 'meso' (health facility level) and the 'micro' (the individual level) often blurred in the empirical data. Hence, we grouped everything that defined the "pragmatic context ${ }^{9}$ " at primary health centres-local values, practices of the community and the health systemunder 'micro contexts'.

To interpret the macro and the micro contexts together, theory offers two broad understandings of policy processes-'top-down' and 'bottom-up'. From a top-down perspective, clear consistent and well-planned policies in a supportive environment lead to successful 
Table 1 Illustrative quotes from Indian policy documents

Focus ideologies

Sample quotes from Indian policy documents

Preindependence

While the word PHC is not mentioned, many broad elements of the approach are justified in India's original vision of the health system

Global influences:

National Health Service, UK
1.1.'The closer the health service can be brought to the people whom it serves, the fuller will be the benefit it can confer on the community. The scheme must therefore provide for the creation of a large number of units.....' (Govt. of India, $1946)^{11}$

1.2.'Suitable housing, sanitary surroundings and a safe drinking water supply are the primary conditions for securing such a measure of environmental hygiene as it is essential to ensure the prerequisites of a healthy life. Without these, our towns and villages will continue to be factories of disease which will help to maintain undiminished the demands on the curative side of the medical services.' (Govt. of India, 1946) ${ }^{11}$

1.3. 'Expenditure of money and effort on improving the nation's health is a gild-edged investment which will yield not deferred dividends to be collected years later, but immediate and steady returns in substantially increased productive capacity. We need no further justification for attempting to evolve a comprehensive plan which must inevitably cover a very wide field and necessarily entail large expenditure, if it is to take into account all the more important factors which got the building up of a healthy, virile and dynamic people' (Govt. of India, 1946) $)^{11}$

1.4.'... in outlining the (short-term) programme, we have tried to bear in mind the necessity for tempering enthusiasm with a sense of reality. In the early years, the lack of sufficient trained staff and of adequate financial resources will inevitably limit the scope of practical achievement.' (Govt. of India, 1946) ${ }^{11}$

\section{Independence to 1970 s}

Originally proposed approach diluted. Ideologies shift to promoting verticalised interventions as 'interim' solutions. Global influences: Rockefeller-focused technomanagerial intervention against malaria, ford foundation-family planning perspectives and funding

2.1 'Even with a $50 \%$ reduction in the rate of population growth between 1966-81 the increase in income will still not catch up with the increase in the population. The Family Planning Programme has, therefore, rightly come to occupy a key position in the Five Year Health Plans.' (Govt. of India, 1961) ${ }^{37}$

2.2. 'Although the Bhore Committee drew attention to the implications of the trends of population growth and suggested action to be taken on this behalf, the full-blooded 'National Family Planning Programme' today is a far cry from the faltering and half-hearted recommendations of that Committee in regard to population control.' (Govt. of India, 1961) ${ }^{37}$

2.3. 'In the early stages, certain services such as those for the control of malaria, filaria, tuberculosis, venereal diseases and leprosy may have to be rendered by special staff but, after adequate control has been attained, such services should form part of and be integrated with the normal activities of a health unit (Plan 2) ${ }^{12}$

\section{Late 1970 s to 1980 s}

Revival of PHC approach. Selective PHC ethos adopted in India.

\section{Global influences:}

WHO: Alma Ata 1978, Unicef-focus on GOBI-FFF
3.1.'We realise that the need for medical relief is so great in our country that to make medical officers concentrate so largely on preventive work may be met with criticism. We have however made this recommendation after careful consideration. Our view is that with the limited staff and funds at disposal of the country, our health programme will show more effective and lasting results if the effort is directed towards the creation of conditions conducive to healthy living instead of concentrating too largely on the administration of medical relief.'(ICSSR and ICMR, 1981). ${ }^{41}$

3.2.'Establishment of curative centres based on western models which are inappropriate and irrelevant to the real needs of our people and the socioeconomic conditions in the country. The hospital-based disease and cureoriented approach to the upper crust of society in urban areas. The proliferation of this approach has been at the cost of providing comprehensive primary healthcare services to the entire population' (National Health Policy 1983) ${ }^{40}$ 3.3 'The non-attainment of the birth rate targets adopted in the Plans is largely on account of our inability to carry forward the (family planning) programme throughout the country with the active involvement of the people. Public enthusiasm and community participation in the programme which is necessary for its success has not been generated in adequate measure.' (Plan 6) ${ }^{12}$ 
Table 1 Continued

\section{Focus ideologies}

Documents argue that to bring equity with limited resources, there is need to focus on issues not covered otherwise by the private sector. The revised health policy NHP 2002 does not mention comprehensive PHC. Global influences:

World Bank,

Global Health Initiatives,

Millennium Development Goals

\section{Sample quotes from Indian policy documents}

4.1. 'Social sector planning therefore ensures that appropriate policies and programmes are formulated, and adequate investment provided by the State so that poor and vulnerable segments of the population can access essential commodities and facilities based on their needs and not on the ability to pay.' $(\text { Plan 10) })^{12}$

4.2. 'During this period, health administrators wish to ensure that budgetary constraints do not reduce the scale, equity, and quality of health service provision, and they are prepared to take difficult decisions toward these ends. It is clearly perceived that any redistributions or cuts in resources to health must be accompanied and offset by operational improvements that enhance efficiency and equity. (World Bank 1992) ${ }^{47}$

4.3. NHP-1983, in a spirit of optimistic empathy for the health needs of the people, particularly the poor and under-privileged, had hoped to provide 'Health for All by the year 2000 AD', through the universal provision of comprehensive primary healthcare services. In retrospect, it is observed that the financial resources and public health administrative capacity which it was possible to marshal, was far short of that necessary to achieve such an ambitious and holistic goal' (National Health Policy 2002) ${ }^{50}$

\section{5 to current}

Documents argue for strengthening health systems by increasing investments; and providing financial protection. Comprehensive $\mathrm{PHC}$ is referred to in terms of service coverage.

Global influences: New Global Health Initiatives. Debates on vertical programme versus horizontal strengthening, Universal Health Coverage.
5.1. The key features of the mission include making public health delivery system fully functional and accountable to the community, human resource management, community involvement, decentralisation, rigorous monitoring and evaluation against standards, convergence of health and related program from village level upwards, innovations and flexible financing and also interventions for improving health indicators (NRHM 2005-12) (1 $^{51}$

5.2. Now 14 years after the last health policy, the context has changed in four major ways. First, the health priorities are changing. Although maternal and child mortality have rapidly declined, there is growing burden on account of noncommunicable diseases and some infectious diseases (National Health Policy $2017)^{54}$

NHP, National Health Policy; PHC, Primary Health Care.

implementation ${ }^{32}$; in this line of thinking, the starting point of interpretation is the policy on PHC adopted (or not) at national and subnational levels, which has consequences that manifest at micro-levels of primary health centres. From a bottom-up perspective, primacy is given to 'agency' and 'discretion' among frontline health workers ${ }^{91026}$; in this line of thinking, the attitudes and behaviour of actors in the frontline based on their norms, values and practical realities-influences $\mathrm{PHC}$ implementation. In this paper, we present the 'macro'

\section{Box 1 Maharashtra context}

Maharashtra is the third largest state in India, considered as one of the more economically advanced states in the country. It performs better than India's average on indicators such as Crude Birth Rate (15.9, India: 20.4), MMR (68 per 100000, India: 167 per 100000) and IMR (19 per 1000 live births; India: 34 per 1000 live births). ${ }^{69}$ As of March 2017, it has 1814 primary health centres, covering a population of 33934 people (as per norm to cover 30000 people). ${ }^{70}$

The following features of the health system can be considered as important in shaping PHC in Maharashtra:

Increasing privatisation: Post structural adjustment policies in the 1990s, state government expenditure on health has decreased as per cent of National State Domestic Product. ${ }^{71}$ In 2015-2016, total state expenditure on health was about $0.6 \%$ of GDSP, and lower than other states like Karnataka $=0.69$, Tamil Nadu $=0.74$ and Kerala $=0.93^{72}$

'Well-functioning' primary health centres: The state has a good network of primary health centres, that rank above Indian average in terms of human resource availability (Filling rural doctor posts has been an important challenge in many states). ${ }^{70}$ Maharashtra is considered as one of the five 'high production' states-for human resources for health ${ }^{53}$; the state has 52 medical colleges of which 23 are public. ${ }^{73}$ Policy dictates a 1-year compulsory rural service stint for undergraduate medical students from public colleges and that, to some extent, fills vacancies at primary health centres temporarily. ${ }^{74}$

Primary health centres as 'public health': In the public health sector of Maharashtra, at district level—the line of authority for 'public health' (primary health centres and below) and 'clinical care' (tiers above primary health centres) are independent. ${ }^{71} 75$ The development of primary health centres that come under 'public health' - has been integrated with the local self-government architecture since 1961; this move has been said to have brought about early expansion of these centres in the state-in comparison to the rest of the country. ${ }^{71}$

In summary, despite having comparatively good infrastructure and human resources in the public sector, utilisation patterns in Maharashtra show a clear preference for the private sector. One analysis of national surveys (2014) found that-for ambulatory care, only $7.5 \%$ of people used primarylevel tiers (India: 8.5\%); 10.4\% used the public hospital (India:17\%) and the rest used private health care. ${ }^{76}$ 
and the 'micro' context separately; and in the discussion, we interpret these findings using both top-down and bottom-up perspectives.

We took written consent from all community participants who could read and write (from a few who could not, we took verbal recorded consent). Consent from health system participants was mostly written; four doctors were not comfortable signing the consent form-we obtained only verbal consent from them. When given permission to record, these interviews were audio recorded. All recordings have been deleted after transcription. All transcript data has been anonymised; and we have not mentioned the name of the district or of particular health centresin order to protect the health system staff. Permissions for the study were taken from state-level authorities.

\section{Patient and public involvement}

The case study in Maharashtra examined community perspectives on primary health centres. For this, we orally discussed with the community and some outpatients at primary health centres about their experiences and expectations from these centres. The community/ patients were not involved in the study design-and we will not be able to disseminate the study results to them.

\section{RESULTS \\ The macro context of primary health in India: a historical review}

\section{Pre-independence}

Many of the core principles of the PHC approach are emphatically defended in the first visionary document of India's health system - the Bhore committee's report $(1946)^{11}$ including ideas of universality ("no individual should fail to secure adequate medical care due to inability to pay'), health as development and the need for easy access to basic care, that integrates the preventive and the curative (table 1, quotes 1.1, 1.2). The report visualises a health system in India with a strong public sector presence that provides comprehensive care to all through a three-tier system (primary, secondary and tertiary) of care (The Bhore committee's visualisation of India's health system was influenced by the National Health Service in the UK. In the short-term plan of the committee, one primary health centre was visualised for every 40000 population. Each primary health centres in the short-term programme was to have 2 doctors, 4 Public Health Nurses, 4 Midwives, 4 trained Dais (local women who served as midwives) and other support staff. In the long-term plan-called as the three million plan, the District Health Organisation was to have a hospital with a bed: strength of 2500 at the district headquarters, 3-5 secondary centres each with 650 beds and 15-25 primary health units with a bed strength population of 10-20 thousand.). It justifies the large expenses of building such a system as being a 'good investment' for the country's progress (table 1 quote 1.3). Primary health centres were part of this original blueprint intended to be first access health facilities, within a three-tier system. A conscious decision was taken to put allopathic doctors in charge of these centres; and tilt their roles towards being 'social physicians'. However, recognising fiscal and human resource constraints in building such a system, the report also proposed a 'short-term' diluted model, intended for the initial years of independence (table 1, quote 1.4).

\section{Independence (1947) to 1970s}

The Bhore committee had advocated a radical shift from the sporadic disease-campaign approach that existed pre-independence. Such a shift required funding support, but post independence, India's political focus was on economic growth through industrialisation ${ }^{33}$ and the health sector lost priority in budget allocations (online supplementary table 2). Health was declared as a "state" subject (states were tasked with developing/maintaining the public health infrastructure), with the federal government offering policy directions and funding priority programme (Plan 1$).{ }^{12}$

In the first decade after independence, building urban hospital infrastructure was given preference ${ }^{34}$-and the first primary health centre was set up only in $1952 .{ }^{35}$ Influenced by the ideologies of the Rockefeller Foundation (that advocated technocentric, antimalaria strategies) and the Ford Foundation (that funded family planning), vertical interventions for these two issuesalong with some attention to tuberculosis, leprosy and smallpox-gained priority (plan 1-4). ${ }^{12} 36$ This change in proposed tactics from Bhore's approach has been explained in Indian policy documents as necessary due to budget and human resource constraints. An urgent need to correct the budgetary neglect of family planning has also been argued for (table 1, quotes 2.1, 2.2, 2.3). By the fourth plan, the budget outlay for family planning had increased dramatically; in plan 1 , of the total plan investment, health expenditure was $3.33 \%$ and family welfare was $0.01 \%$; in plan 4 , health expenditure was $2.13 \%$ and family welfare was $1.76 \%$ (online supplementary table 3 ). A review in 1961 showed that primary health centres fell short of Bhore's recommendations in terms of numbers/ coverage and were severely understaffed. ${ }^{37}$ In addition, staff of the family planning programme had begun to dominate these centres. ${ }^{34}$

\section{Late 1970 s to 1980 s}

In India, the Alma-Ata declaration brought into policy focus the original ideals of the Bhore committee-in a globally ratified package. In this period, the works of eminent sociologists and policy documents in Indiaendorse the PHC approach-reiterating disadvantages of 'western' curative models, the need to overcome cultural gaps between the people and the system, and provision of care close to people ${ }^{38-41}$ (table 1, 3.1 and 3.2). The resurgence of malaria in India, in this period, has been argued as the inability of a poorly-funded health system to 'maintain' programme results (plan 4$).{ }^{12}$ In addition, 
30000

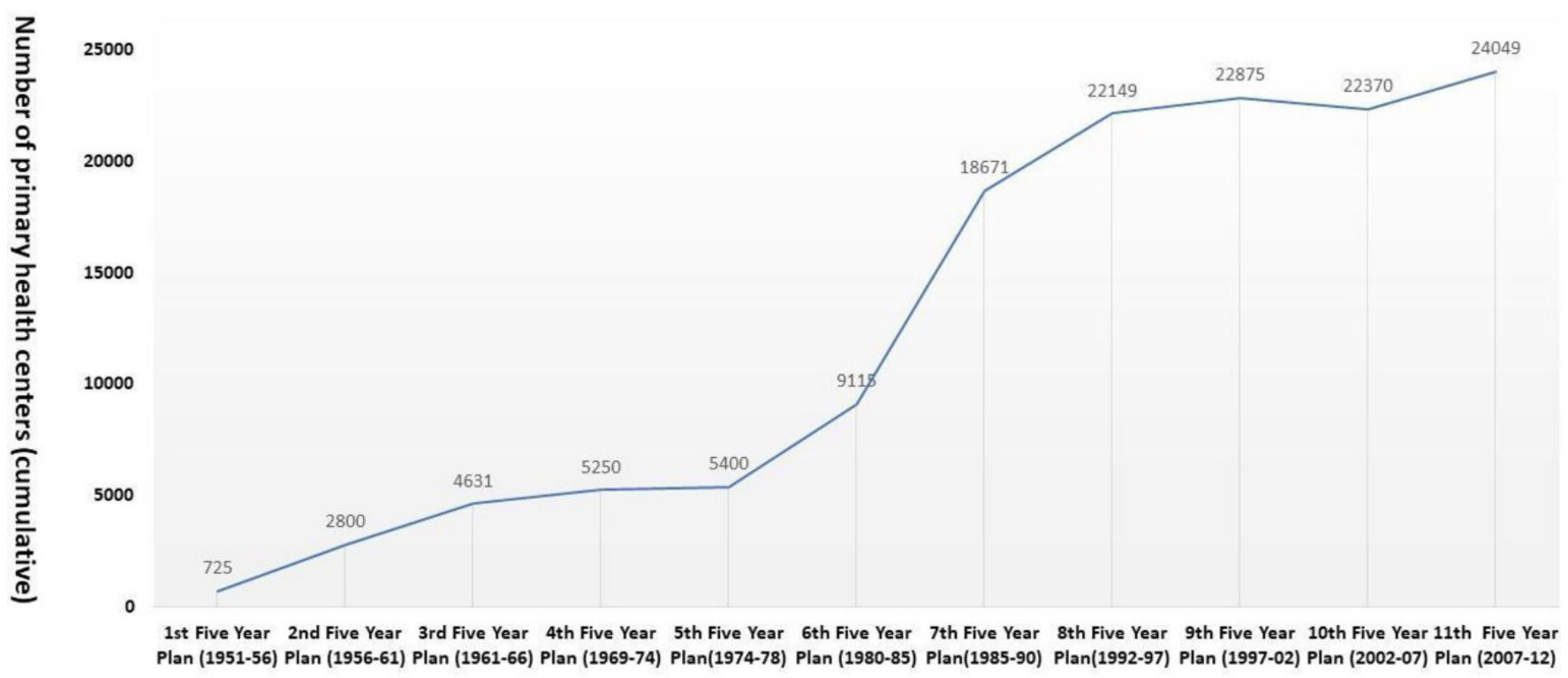

Time period

Figure 2 Expansion of primary health centres in India.

coercive sterilisation strategies by the Indian government had tarnished the reputation of the family planning programme; thus, ideologies that emphasised community participation (in lieu of force) were politically championed (plan 6) ${ }^{12}{ }^{42}$ (table 1, quote 3.3). All this led to increased funding for primary health centres and their rapid expansion (plan 5,6). ${ }^{12}$

Soon after Alma-Ata, its vision was revisited in international forums; and a selective package of interventions was advocated instead. ${ }^{43}$ For India, the selective ethos that had already been rooted in the system was easy to maintain. Thus, while numbers of primary health centres rapidly increased (see figure 2), these still offered limited services. National surveys (1986-1987) indicate that people sought outpatient care mainly at private doctors $(53 \%)$ or the public hospital $(17 \%)$; only $4.9 \%$ used primary health centres. ${ }^{44}$

\section{Late 1980s to 2005}

A move towards neoliberal ideologies (free market, attenuation of the government role, fiscal austerity) began in India in the late 1980s, though structural adjustment policies in the country were officially launched only in the early 1990s. ${ }^{45}$ These policies advocated cost-containment strategies in the public health sector and a push to move non-priority services to the private sector. ${ }^{46}{ }^{47}$ Written policies within India rationalise these reforms by arguing that during a time of fiscal constraints, equity can only be achieved by targeting demographics, geographies and type of services (table 1, quotes 4.1,4.2). Other new global health assistance players also arose during this period; and international attention shifted to reproductive and child health, HIV/AIDs, tuberculosis and vector-borne diseases in line with the Millennium Development goals. ${ }^{48} 49$ The revised health policy 2002 reflects these developmentsbut is silent on the notions of 'comprehensive PHC' that the previous policy had defended eloquently ${ }^{50}$ (table 1 , quote 4.3). The expansion of primary health centres stopped gradually (figure 2). The basket of services at primary health centres remained restricted-though the disease portfolio (and extent of technology/ drugs available to vertical programme) changed.

\section{From 2005 to present}

In 2007, an initiative of India's central government, the National Rural Health Mission-whose ideologies supported horizontal strengthening of services, community involvement and bottom-up planning (table 1, quote 5.1)-increased overall financing to the health sector-focussing mainly on states with poor health indices. ${ }^{51}$ The mission carried out substantial infrastructural upgradation and contractual staff recruitment at primary health centres. ${ }^{52}$ The global Universal Health Coverage discourse caught on in India around 2010; and brought attention to the need to reduce out of pocket expenditure and provide financial protection to people. ${ }^{53}$ Current political discourse, reflected in the revised policy of 2017, prioritises (1) the need for financial protection for hospitalised care (justified in terms of increasing out-of-pocket expenditures) and (2) the inclusion of non-communicable disease interventions at the periphery (justified in terms of changing epidemiological burden) (table 1, quote 5.2) ${ }^{5455}$ In the revised policy, 'comprehensive PHC' mainly refers to the expansion of primary-level service packages to include non-communicable diseases. ${ }^{54}$ 
In summary, the public health system in India has been subjected historically to gross underfunding, and public health expenditure in India is one of the lowest in the world (at US\$39 per capita, compare China: US $\$ 203$, Sri Lanka: US\$66, Bangladesh: US\$14, Brazil: US\$483; year 2011).$^{56}$ The development of the public health system and strengthening of its infrastructure has happened in small spurts. But piecemeal vertical solutions have mostly been the preferred operational choice; defended by policy discourse in terms of epidemiological situations, budget and human resource constraints and prioritisation. This kind of macro context has led to primary health centres that offer only selective services, focus heavily on programme of national (and international) priority at any given point in time and work in an overall poorly funded health system.

\section{Micro context}

To situate the experience of the primary health centres, box 1 provides a brief outline of the state context.

Summarising from box 1, the state context highlights the existence of a good network of primary health centres, with policies to combat human resource vacancies at these centres, indicating a history of political commitment to this cause. Post 1990s, however, overall state expenditure on health has reduced (in comparison to other Indian states that had made similar social progress). Further, national (and international) emphasis on priority interventions- has resulted in only 'essential', public health services being available at primary health centres in the state, mostly delivered through vertical programmes. Such a state-context ensconces the micro level issues below:

\section{Most doctors do not find value in their roles at primary health centres}

All doctors we interviewed view primary health centres mainly as platforms for national programmes and schemes; since much of their time as well as the targets given to them by higher authorities focused around these activities. They perceive work at these centres to be focused on 'preventive care' activities that involved acquiring administrative rather than clinical skills. This kind of work is clearly not of value to doctors. For most doctors, the only clinical work available at these centres is running the Out Patient Department clinics (OPDs). But, at an organisational level, there are no targets or incentives for delivering OPD services. In addition, most doctors do not view primary care OPDs as 'good clinical work'; where their professional expertise could be used fully (see box 2). Further, most doctors feel that good clinical work at primary health centres is hampered by the lack of drugs and supporting facilities such as functional operation theatres, diagnostics and equipment.

In short, most doctors are not happy at primary health centres; and said that they would prefer private sector jobs, that were regarded as more lucrative, or express a preference for working at higher tiers of the public health system-where the clinical work is perceived as more challenging. In the region, we collected empirical data from, many posts for second doctors at primary health centres are vacant-in a desperate attempt to fill these posts the government has enforced a compulsory 1 -year stint at primary health centres for new medical graduates. The graduates we interviewed do not plan to stay on beyond completion of this stint.

The services offered at primary health centres often do not meet communities' expectations in contrast to services offered by local private practitioners

The community views and evaluates primary health centres like any other curative health facility on the basis of OPD services (and some inpatient services). Community expectations are clearly centred around these centres being good, primary-level curative care facilities-dispensing a variety of free drugs and treatments-and most centres could not live up to these expectations. First, primary health centres, designed under the ethos of 'selective care', offer a very narrow range of curative health services-and have only a few generic drugs available. The community feels that these centres dispensed the 'same medicines for all diseases'; and even those medicines were not given at times due to stockouts (see box 2). Second, these centres function mostly from a 'rational clinical care' perspective; and do not cater to demands for instant relief' by the community. Hence, the treatment offered by primary health centres is often in contrast to those offered by local private practitioners. These practitioners, not bound by the strict regulations that government doctors had to adhere to, cater to 'mass appeal'-by administering strong drug combinations that provide instant relief, and intravenous rehydration therapies as per the patients' demand (even when these treatments were clinically irrational). These practices set a different set of expectations in the community about primary-level carewhich primary health centres could not address. In addition, strained community-provider relationships (described in the next section) adversely affect people's opinions of these centres. All these factors together make the local private practitioner the first access point to primary-level curative care. Primary health centres today, are, at best, accessed for select services such as immunisation, family planning, for antidotes to animal bites and treatment of certain diseases like tuberculosis and malaria.

\section{Strained community-staff interactions further deter utilisation}

A common community complaint is the lack of 'attention' given to them at primary health centres. Attention appears to comprise (1) the doctor taking time to understand the issues, (2) doctor using the stethoscope and touching the patient during the interaction, (3) support staff who speak politely and follow doctors' instructions and (4) the prescription of strong medicines. All this, the community feels, does not happen in most primary health centres (see box 2).

Doctors' notions of attention are different from those of communities. For one, most doctors do not believe that 


\section{Box 2 Micro context: illustrative quotes}

\section{Most doctors do not find value in their roles at primary health centres}

'Even for a general medicine graduate the primary health center is not a great place... in his course, he learns about many good-good medicines... and here he will be confined to using 4-5 of them here....and can't use his knowledge....so why will he come? Coming here is not an issue... but without drugs and equipment, no one will work. (Medical Officer, 23 years, Female, Fresh graduate)

'It is very horrible work at the primary health centre. At the rural hospital (second tier of the system), work is more clinical. If you are a clinician by heart, then you should go to there and not here. Primary health center work is only meant for people who are administratively strong- management is their strength" (Medical Officer, Male, 45 years, experience-8 years, has also worked in other tiers of the system for 5 years).

The services offered at primary health centres were few and often did not meet communities' expectations

P1: ... it is like diseases are all of different types. Then they (at the center) give two medicines to all type of illness. All are similar they don't change, this is what he wants to say.

Moderator: Doesn't it happen in private?

P4: In private, tablets are powerful. Whatever the disease is medicine for that disease only it is given, here it is not like that.

P5: Quick difference is not felt in government.

P1: The power of government medicines is less. They are all simple. The medicines are very normal. What they say in government, same type of medicine is given no matter which disease you go for.... the tablets are same only and we don't get any difference that fast. (Community discussion, mixed gender group, location: far from district head-quarters (>40 km), the primary health center was about 1 kilometre away from place of discussion, and less than 10 years old)

\section{Strained community-staff interactions further deter utilisation of services}

P1: nobody takes care there (at the primary health center)

Moderator: What kind of care?

P2: Taking care of us means, give medicine and injections and tablets to patients, give good service, check-up...

$\mathrm{P} 1$ : Whatever is paining you have to treat, accordingly. Give saline if we ask.

P6: ... giving service on time...

P2: Here in the primary health center, if ever we go, they don't even look at us, never take BP, nothing ever, this is their method....

P7: And if you go there, get the (case) paper issued...then wait in line...even then they don't treat properly, don't touch us, they just give the medicine and ask us to go. (Community discussion, Mixed gender group, Location: Far from district head-quarters (>60 km), primary health center in the same village as place of discussion, center more than 10 years old).

"Once there was a drunk man...came in demanding I give him IV at once since his hands and legs are paining. Was shouting here -standing right where you are... Gets angry because I gave the IV line to the other patients. I have only limited IV lines- and others are also patients... how can we attend to everyone in a fast way" (Nurse, 25 years, Female, experience- 5 years)

\section{Out-patient care gets low preference-within target-oriented structures}

The primary health centers' biggest role is in national program... because of the national program and their targets, there is less focus on the OPD...there are a lot of targets...conduct deliveries... do vaccination...then all new programs have their own targets. (Medical Officer, Male, 39 years, experience-12 years).

\section{Risk-averse behaviours and poor referral practices deter its function as a 'link' to higher tiers.}

Our senior used to tell us 'if you want to take a risk, then you do it elsewhere .... if you want to play, then do it only if you have the guts... if you want to play, do it elsewhere or in your private practice.... not in the primary health centre...nothing happens here and don't try to change things... Also, the issue is that if there is some issue...even a tiny issue, at least five journalists will turn up here... and we have to answer them...and they will dramatise the episode.' (Medical Officer, Male, 33 years, experience- 9 years).

the type of ailments people came with to primary health centres require more than a quick appraisal. This quick appraisal and the small window of contact with the doctor sometimes has adverse consequences. For instance, one patient we met-who reported throat pain-had not informed the doctor at the centre of her prior visits to a specialist who suspected throat cancer. When asked why she did not share this information, her answer was that the doctor never asked. She also suspected the doctor of pocketing throat-related medication from the centre. This case is also an example of suspicious attitudes of the community towards primary health centre staff. Indeed, the community, in general, has poor views about all public institutions as well as employees who work at these institutions (It must be noted that though people relied on local private practitioners for first access, the community had developed a sense of wariness about these practitioners; people believed that private practitioners were sometimes money-minded, had tie-ups with drug stores and prescribed unnecessary and costly medicines).

The wariness of the community towards the staff is not a one-sided phenomenon. Primary health centre doctors express frustration over patients who demanded drugs like cough syrups and intravenous rehydrationdespite having no clinical need. Nurses and laboratory technicians report of people fighting with them over the non-arrival of laboratory reports or unwillingness to wait in the line for their turn (see box 2). In summary, mutual wariness between the community and staff at primary health centres deters a trust relationship, essential to the provision of good primary-level care.

\section{Outpatient care gets low preference-within target-oriented} structures

The biggest contribution of primary health centres within the health system is perceived-by almost all 
health system staff-to be in operationalising vertical programme and schemes (see box 2). This perception stems from a complex interaction of factors-including strict targets set within the system for vertical programme; and targets which the staff feel compelled to complete because they are held accountable only for these within bureaucratic work environments. Staff express more concerns on how they 'report' the schemes-rather than how they carry out activities under various schemes. Also, activities whose targets (numbers) are checked less frequently by higher level managers get less attention. Within such target-oriented vertical structures, there is little support and encouragement for activities-like the OPD-from the authorities. While two OPDs are mandated in a day, it is an accepted practice to conduct only one. In short, basic curative care at primary health centres has been side lined; this fact, exacerbated by the lack of drugs and equipment, in an environment of mutual wariness between the community and health staff, has made poor quality OPDs a harsh reality at these centres.

Risk-averse behaviours and poor referral practices at primary health centres deter its function as a 'link' to higher tiers

Doctors perceive themselves as 'professionally isolated' at primary health centres and in practice-feel delinked from the referral tiers. They express concerns about having to deal with consequences of adverse events (such as a death or a mishap) with no peer support. This isolation, combined with drug-stock outs and lack of equipment/ diagnostics, has led to 'risk-averse' behaviour among doctors, resulting in an increased number of referrals from primary health centres than necessary from a clinical angle (see box 2).

Health staff at primary health centres do not see the referral tiers as 'support' to their work: when cases were referred, they see this as passing on the legitimate clinical work of the higher tiers. This 'referral' is not perceived as making any difference to the goals of the centres-whose work is viewed as that of programme operation. Hence, staff do not think of it as their duty to follow up on referred cases (The exception to this was delivery. In Maharashtra, recent efforts have been made to strengthen ambulance linkages between the primary health centres and the higher tiers- to ensure that referral during delivery was timely. The primary health centre was held accountable for such referrals).

Consequently, instead of becoming an integral link in a referral system, primary health centres have become institutes for 'preventive' issues and 'programmes' that refer even primary-level cases. Hence, these are thought of as 'too basic' and places that 'can't really do much'. Disparaging attitudes towards primary health centres are encountered in conversations with almost all health staff, but most explicit among doctors and administrators.

A summary of the micro context is presented in table 2 .

\section{DISCUSSION}

What has happened to primary health centres in India illustrates some of the challenges to the implementation of the PHC approach. Figure 3 summarises the experience reported here. Below, we explain the situation of primary health centres using both top-down and bottom-up perspectives of policy change.

From a top-down perspective, the situation of primary health centres in India can be considered as a consequence of changing national ideologies and fiscal priorities. The ideological climate that favoured the development of primary health centres existed only in small spurts; and these centres lost out on funding when competing ideologies (such as that of neoliberalism or vertically funded aid) gained prominence. Thus, many states in India have primary health centres with severe infrastructural constraints. In the state of Maharashtra, however, early commitment to expansion of primary health centres through decentralised mechanisms and availability of human resources and supporting policies to combat vacancies have led to primary health centres with better infrastructure than Indian averages. Despite this, a decrease in public funding for health since the 1990s; combined with an increased focus on delivery of 'essential' public health services-has had consequences for primary health centres in the state. In particular, the operational policy choice of 'selective' services at state (and national levels) manifests in the form of few services being available at primary health centres, mostly pertaining to vertically run programmes. These services are based on health system priorities rather than the felt needs of people.

From a bottom-up perspective, the issues become more complex. The manifestation of the above macro issues (the provision of select services in primary health centres, in an underfunded context) interact with local actors' norms and behaviours. Doctors, whose ambitions tend towards specialisation find little professional fulfilment in providing primary-level care services-even more so, in situations where the services they can offer are extremely restricted. The institutional context of primary health centres-having no targets for outpatient care, vertical reporting structures, and the tacit promotion of risk-averse behaviours-further lowers the attention given to outpatient care. Patients find few services offered by primary health centres relevant to their needs (a manifestation of the 'selective care' macro context); but this situation is worsened by healing norms in the community that favour instant relief (norms that private practitioners cater to, but primary health centres cannot) - and a deep-seated suspicion of public sector employees. All this has led to primary health centres today that are a far cry from PHC principles of first access and comprehensive care provision.

We have used the example of primary health centres to illustrate some of the complexities in implementing PHC. Many issues encountered in the macro contextcompeting neoliberalist ideologies, the pervasiveness of vertical funding, low budgets for PHC, and more recently, PHC being subsumed inside the UHC debates-have been 
Table 2 Micro context of primary health centres in India (source: data from interviews and focus group discussions)

Actors perceptions

Health system

- Primary health centres viewed as a vehicle for programme and schemes, rather than as a provider of integrated care.

- There is little financial support and encouragement of activities - like the OPD-from the authorities.

- Primary health centres viewed with derision within the health system as a hospital that does not have many facilities.

- Primary health centres viewed (by doctors) as place where professional support from peers is absent. Doctors work gets reduced to administrative work.

- Few drugs available for curative care at these centres. The higher tiers better suited for curative care.

\section{Community}

- Primary health centres viewed as a small hospital that has nothing much in terms of facilities or drugs.

- Community finds very few services of primary health centres relevant to their basic curative care needs.

- Primary health centres sometimes treated as a pharmacy to obtain a stock of drugs or tonics.

- Mismatch on perceptions of what primary care entailsbetween community and the health system actors.

- Community often does not understand the logic behind having many tiers of care. Community views referral with suspicion (as staff shirking their duty).

Expectations from primary health centres: Guaranteed presence of the doctor, attention from the doctor and other staff, strong drugs and more 'variety'; all laboratory reports must come on time. Instant relief must be obtained; and the patient must not be asked to come again and again. Even if primary health centres are geographically a little distance away, these can be visited if the trip is worth the effort.

\section{Actor practices}

Health system

- Non-incentivised OPDs get less attention

- In coping with too many schemes and programme, health workers concentrate only on activities with targets

- There is focus on reporting activities rather than doing them

- There is no incentive for not referring/ treating at primary health centres

- Doctors hesitate to take risks due to fear of punitive action and lack of peer support (nurses are protected by doctors to some extent)

\section{Community}

- Healing norms in the community are oriented towards instant relief-this is mismatch with the practices at primary health centres. However, the local private practitioners cater to these needs.

- There is wariness about public institutions and their employees in the community

- Doctors at primary health centres process people in the OPD mechanically. Community not satisfied with such processing

- Community dissatisfied with the experience at these centres nurse interaction; waiting time; staff's way of speaking to them and delay in laboratory reports. (especially in contrast to private practitioners)

- Community members demand clinically irrational treatments at primary health centres.

OPD, Out Patient Department.

discussed in global literature. ${ }^{4-7}$ These macro issues have been shown to manifest at micro-levels of the system - for instance, Baum et al poignantly illustrate how neoliberal ideologies manifest at primary health centres in Australia, reducing the envisaged community engaged, comprehensive service model to mere outreach centres. ${ }^{57}$ There is less literature on how the 'day-to-day' realities of the health system (the organisational culture, actors' values and actions) affect PHC implementation. In our case study, these realities include an organisational context that tacitly promotes risk-averseness; the neglect of outpatient care in favour of targeted activities; doctor's mismatched professional aspirations; and mismatched expectations of care between the community and staff. These issues-in addition to the macro context can be thought of as important influencers of policy success. ${ }^{8-1026}$

In India, structural deficiencies and staff vacancies at primary health centres are so striking in some areas ${ }^{13-15}$ that it is a challenge to look beyond these issues. In a state like Maharashtra, these issues are not apparent and primary health centres have been called 'well-functioning'. But the term 'well-functioning' masks the fact that even the country's 'good' primary health centres still cater to only a small portion of people's needs, are not first access points, get bypassed and fail to become the 'heart of a people-centred integrated system of care'. ${ }^{58}$ Even in the state of Tamil $\mathrm{Nadu}$, which is well known for good quality drugs in the public system - and 'good health at low cost ${ }^{59}$ - the utilisation of outpatient primary-level services in the rural public sector is about $10 \% .{ }^{60}$ Thus, what remains today of primary health centres, even at their best, is an empty shell, stripped of the original PHC philosophy. Andrew et al argue that such interventions embody the 'technique of successful failure ${ }^{, 61}$ for the mimicked form of primary health centres, though an empty shell, can look like a successful PHC intervention.

In India, people spend large amounts on outpatient care for 'day-to-day' ailments—as much as hospitalisation costs. ${ }^{62}$ These out-of-pocket costs can be minimised by the use of primary health centres. In addition, primary health centres are one of the few places where the rural community can access a qualified doctor-for presently, it is unqualified practitioners who provide most primary-level care. ${ }^{63} 64$ Hence, it is imperative that primary health centres embody core PHC principles- and become first access institutions that provide comprehensive care, respond to community needs, and guide towards specialty care. In box 3, we have tried to summarise some directions for primary health 


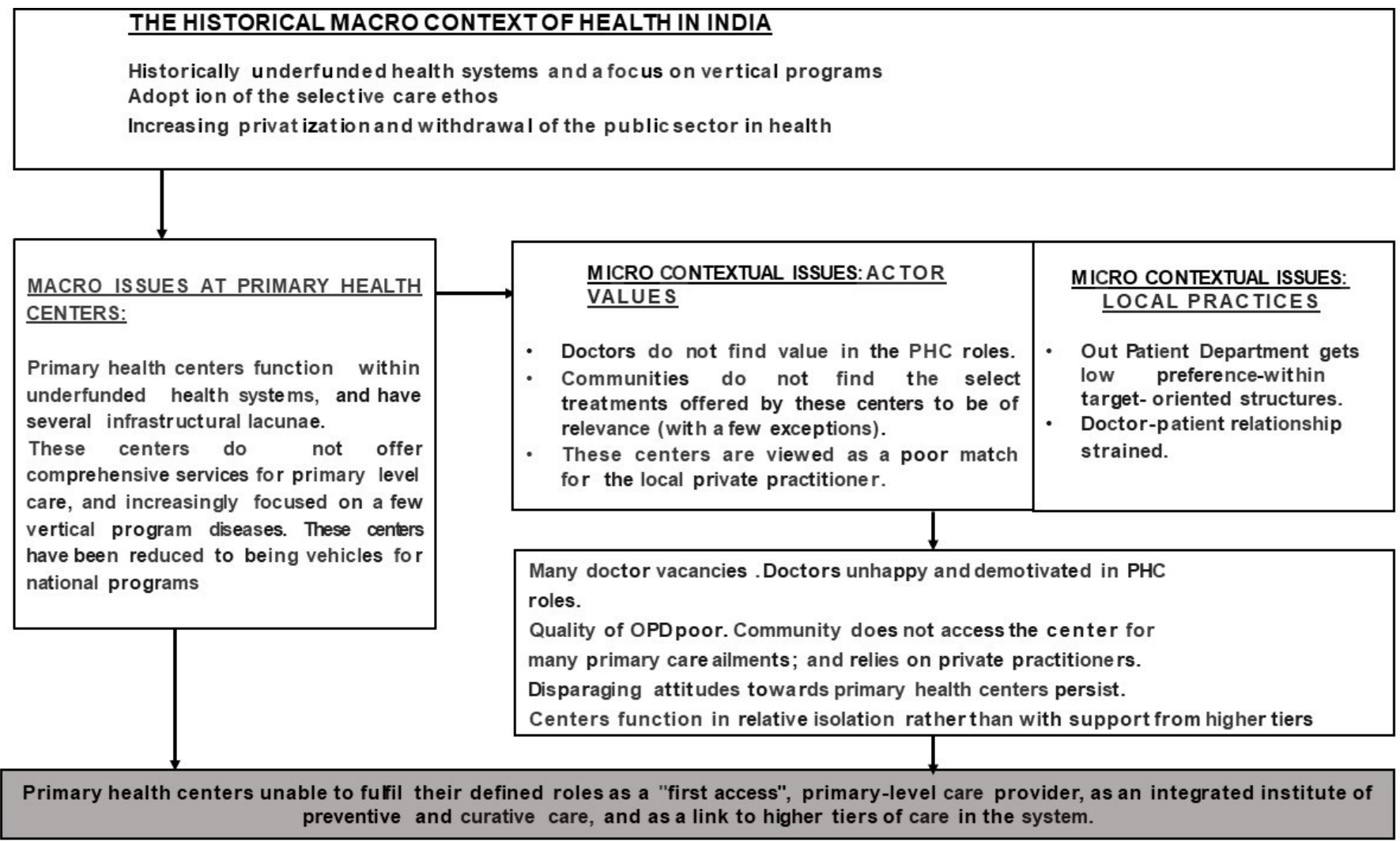

Figure 3 Summary - what happened to primary health centres in India.

centres in India. Since the situation in India mirrors the condition of peripheral health centres in many LMICs, ${ }^{65-68}$ elements of box 3 may be relevant across countries.

In summary, this paper, using the example of primary health centres, illustrates some of the contextual complexities of PHC implementation-which can be at macro levels (pertaining to ideologies and fiscal priorities) and at micro levels (pertaining to the norms and everyday realities of front-line actors) of the health system. It cautions against masked successes - that even while appearing to work well, in reality, maybe disengaged from the philosophical orientation of PHC.

This paper has some limitations. In the macro context, the complexities of interactions between global and national ideologies have been addressed only briefly. In addition, our micro level evidence is drawn from one state,

\section{Box 3 Directions for Indian primary health centres}

Ideological: Refocus on PHC principles of universal access, provision of comprehensive care close to the community, taking into consideration community needs.

Policy directions: Increased funding to primary health centres, expansion of the current 'service model' of primary health centres, improvement of institutional practices and building of community trust.

Approaches

Focus on horizontal strengthening of health systems through improving infrastructure, human resources and drugs-in conformation to national quality standards.

- Expand the 'service model' of primary health centres to provide comprehensive care - through widening the basket of services provided at primary health centres.

Rethink about the roles of doctors at primary health centres to ensure better utilisation of their professional expertise.

- Expand the roles for nurses and other practitioners at primary health centres (and consider advanced trained nurse practitioners and non-physician clinicians as main providers at these centres).

Balance the attention given to indicators of vertical programmes and outpatient care at primary health centres in district and state-level reporting systems.

- Provide routine mentorship and backing/support for staff at primary health centres to counter professional isolation and risk-aversion tendencies.

- Promote bottom-up consideration of issues at primary health centres (taking into account community needs); and develop institutional mechanisms for arriving at participatory solutions.

- Community and health system level messaging to deal with disparaging attitudes towards primary health centres and primary-level care in the public system. 
and infrastructural conditions in other states are different. Also, we did not look into issues of local ownership or intersectoral coordination at primary health centres even though these issues also embody the PHC approach. In our case, people did not emphasise geographical distances as barriers to access-this could be because of the better developed transport in the study area. Also, we could not elicit caste barriers to access in our case study; which have been shown as important in other studies. ${ }^{38} 62$ Given these points, our evidence is only illustrative of the complexities of implementation.

Acknowledgements This paper has been funded through the Health Policy Analysis Fellowship programme, supported by the Alliance for Health Policy and Systems Research, Switzerland. We acknowledge the mentor team of the fellowship programme-Dr. Irene Agyepong, Dr. Jeremy Shiffman and Dr. Maylene Shung-king; and all the fellows of the programme-for their very useful comments and inputs on the paper-during two workshops held in December 2017 and October 2018. We thank the Center for Social Medicine, Pravara Institute of Medical Sciences, in Ahmad Nagar, Maharashtra, for data collection and logistical support, in particular, the interns who worked with us and faculty, Dr. Somasundaram and Dr. Thitame. We thank the community and the health staff who shared their valuable thoughts with us during the study. We particularly thank Dr. Sundararaman, Tata Institute of Social Sciences, Mumbai, for his comments on the study idea, early findings from the study and reflections on this paper. We specially thank Dr.Jaswal, Deputy Director, Tata Institute of Social Sciences, Mumbai, for her numerous inputs into study design and protocol development; and comments on initial analysis of study results.

Contributors SR developed the initial design for the study, with mentorship from LG and SM. Data collection was done by SR, and both LG and SM commented on initial data summaries and the analysis. The first draft of the paper was written by SR, and reviewed by SM and LG. The final draft has been reviewed by all three authors. SR is the guarantor of the paper.

Funding This study is funded through the Health Policy Analysis Fellowship programme, supported by the Alliance for Health Policy and Systems Research, Switzerland, and managed through the University of Cape Town, South Africa. The Alliance for Health Policy and Systems Research funded the Health Policy Analysis Fellowship programme to build the capacity of doctoral level students to undertake research in this field. The first author of this paper was awarded this fellowship.

Competing interests None declared.

Patient consent for publication Not required.

Ethics approval Ethical approval for the study was taken from the Institutional Review Board at the Tata Institute of Social Sciences, Mumbai, India, in April 2018.

Provenance and peer review Not commissioned; externally peer reviewed.

Data sharing statement № additional data are available.

Open access This is an open access article distributed in accordance with the Creative Commons Attribution Non Commercial (CC BY-NC 4.0) license, which permits others to distribute, remix, adapt, build upon this work non-commercially, and license their derivative works on different terms, provided the original work is properly cited, appropriate credit is given, any changes made indicated, and the use is non-commercial. See: http://creativecommons.org/licenses/by-nc/4.0/.

\section{REFERENCES}

1. World Health Organization. Primary health care: report of the International Conference on primary health care Alma-Ata, USSR, 6-12 September 1978. Geneva: World Health Organization, 1978.

2. United Nations Development Programme. Sustainable development goals, 2016. Available: http://www.undp.org/content/undp/en/home/ sustainable-development-goals.html [Accessed 25th Sep 2018].

3. World Health Organization. Global conference on primary health care: towards health for all, 2018. Available: http://www.who.int/ mediacentre/events/2018/global-conference-phc/en/ [Accessed 17th Nov 2018].

4. Peoples Health Movement. 4th health assembly. Alternative civil society Declaration on primary health care. Available: https:// phmovement.org/wp-content/uploads/2018/10/AlternativeCSAst anadeclaration110ct.pdf [Accessed 2nd Feb 2019].
5. Lawn JE, Rohde J, Rifkin S, et al. Alma-Ata 30 years on: revolutionary, relevant, and time to revitalise. Lancet 2008;372:917-27.

6. Rifkin S. Health for all and primary health care, 1978-2018: a historical perspective on policies and programs over 40 years. Oxford Research Encyclopedia of Global Public Health. 2018.

7. Druetz T. Integrated primary health care in low- and middle-income countries: a double challenge. BMC Med Ethics 2018;19.

8. Gilson L. Everyday politics and the leadership of health policy implementation. Health Systems \& Reform 2016;2:187-93.

9. Olivier de Sardan J-P, Diarra A, Moha M. Travelling models and the challenge of pragmatic contexts and practical norms: the case of maternal health. Health Res Policy Sys 2017;15.

10. Lipsky M. Street-Level bureaucracy: dilemmas of the individual in public services. New York: Russell Sage Foundation, 1980.

11. Government of India. Report of the health survey and Development Committee, vol. II (chairman: Bhore. Delhi: Manager of Publications, 1946.

12. Government of India. Planning Commission of India. five year plans \# 1-10. Available: http://planningcommission.gov.in/sectors/health. php?sectors=hea [Accessed 22nd Jul 2018].

13. Sodani $P$, Sharma K. Strengthening primary level health service delivery: lessons from a state in India. J Fam Med Primary Care 2012;1:127-31.

14. Powell-Jackson T, Acharya A, Mills A. An assessment of the quality of primary health care in India. Econ Polit Wkly 2013;48:53-61.

15. Bhaumik S. Health and beyond strategies for a better India: concept paper on primary health care in India. J Fam Med Primary Care 2014;3:94-7

16. Gautham M, Binnendijk E, Koren R, et al. 'First we go to the small doctor': first contact for curative health care sought by rural communities in Andhra Pradesh and Orissa, India. Indian J Med Res 2011;134:627-38.

17. May C, Roth K, Panda P. Non-degree allopathic practitioners as first contact points for acute illness episodes: insights from a qualitative study in rural northern India. BMC Health Serv Res $2014 ; 14$.

18. Government of India. Report of the Taskforce on comprehensive primary health care roll-out. New Delhi: Ministry of Health and Family Welfare, Government of India: 2014-5.

19. Walt G, Gilson L. Reforming the health sector in developing countries: the central role of policy analysis. Health Policy Plan 1994;9:353-70.

20. Pawson R, Tilley N. Realistic evaluation. London: Sage, 1997.

21. Collins C, Green A, Hunter D. Health sector reform and the interpretation of policy context. Health Policy 1999;47:69-83.

22. Leichter HM. A comparative approach to policy analysis: health care policy in four nations. Cambridge: Cambridge University Press, 1979.

23. Koduah A, van Dijk H, Agyepong IA. The role of policy actors and contextual factors in policy agenda setting and formulation: maternal fee exemption policies in Ghana over four and a half decades. Health Res Policy Sys 2015;13.

24. Fischer F. Reframing public policy. Discursive politics and Deliberative practices. Oxford: Oxford University Press, 2003.

25. Government of India. Report of the national commission on Macroeconomics and health. New Delhi, 2005.

26. Hill M, Hupe P. Implementing public policy. London: Sage, 2006.

27. Government of India. Indian public health standards. Revised guidelines. New Delhi: Ministry of Health and Family Welfare, Government of India, 2012.

28. Miles MB, Huberman AM. Qualitative data analysis: an expanded Source- book. London: Sage, 1994.

29. Creswell JW. Qualitative inquiry and research design-Choosing among five approaches. London: Sage, 2007.

30. Ricketts Julie-Ann, Ricketts JA. The making of Jamaica's 'National Policy for Persons with Disabilities 2000': macro, meso and micro factors. Disability \& Society 2010;25:551-64.

31. Mirzoev T, Das M, Ebenso B, et al. Contextual influences on the role of evidence in health policy development: what can we learn from six policies in India and Nigeria? evid policy 2017;13:59-79.

32. Mazmanian D, Sabatier P. Implementation and public policy. Glenview: Scott, 1983.

33. Guha R. India after Gandhi. New Delhi: Picador India, 2017.

34. Duggal R. Evolution of health policy in India. center for enquiry into health and allied themes, 2006. Available: http://www.cehat.org/ cehat/uploads/files/a147.pdf [Accessed 23rd Dec 2018].

35. Bhattacharya SN. Community development: an analysis of The programme in India. Calcutta: Academic Publishers, 1970.

36. Minkler M. Consultants or colleagues: the role of US population advisors in India. Popul Dev Rev 1977;3:403-19. 
37. Government of India, Ministry of Health and Family Welfare. Report of the Mudaliar Committee. New Delhi, 1961.

38. Banerji D. Health and family planning services in India: an epidemiological, Socio-cultural and political analysis and a perspective. New Delhi: Lok Paksh, 1985.

39. Qadeer I. Beyond medicine: an analysis of health status of Indian people. Think India 1990;2:97-8.

40. Government of India. National health policy. New Delhi: Ministry of Health and Family Welfare, Government of India, 1983.

41. Indian Council of Social Science Research and Indian Council of Medical Research. Health for all- an alternate strategy. Pune: Indian Institute of Education, 1981.

42. Gwatkin DR. Political will and family planning: the implications of India's emergency experience. Population and Development Review 1979;5:29-59.

43. Walsh JA, Warren KS. Selective primary health care: an interim strategy for disease control in developing countries. N Engl J Med 1979;301:967-74.

44. National Sample Survey Organisation. New Delhi. Government of India: 1986-7.

45. Sen G, lyer A, George A. Structural reforms and health equity: a comparison of NSS surveys, 1986-87 and 1995-96. Econ Polit Wkly 2002;37:1342-52.

46. World Bank. World development report 1993: investing in health. 1993. Washington DC: World Bank.

47. World Bank. India health sector financing: coping with adjustment opportunities for reform, June 30, 1992. New Delhi: World Bank, Population and Human Resources Operations Divisions, South Asia Country department II,: 1992.

48. United Nations. "United Nations Millennium Declaration." New York, 2000. Available: http://www.un.org/millennium/declaration/ares552e. htm

49. Carlson C. Mapping global health partnerships: what they are, what they do and where they operate. London: DFID Health Resource Centre, 2004.

50. Government of India. National health policy. New Delhi: Ministry of Health and Family Welfare, Government of India, 2002.

51. Government of India. National rural health Mission-Framework for implementation 2005-12. New Delhi: Government of India, 2005.

52. Government of India. Planning Commission. Evaluation study of national rural health mission (NRHM) in 7 states. New Delhi: Government of India, 2011.

53. Government of India. The planning Commission. High level expert group on universal health coverage. New Delhi: Government of India, 2011.

54. Government of India. National health policy. New Delhi: Ministry of Health and Family Welfare, Government of India, 2017.

55. Government of India. Situation analyses to the National health policy. New Delhi: Ministry of Health and Family Welfare, Government of India, 2017.

56. Kurien OC. Financing healthcare for all in India: towards a common goal. Oxfam India Working paper series, 2014. Available: https:// www.oxfamindia.org/sites/default/files/WP-Financing-Healthcarefor-All-In-India-29-05-2015-EN_0.pdf

57. Baum F, Freeman T, Sanders D, et al. Comprehensive primary health care under neo-liberalism in Australia. Social Science \& Medicine 2016;168:43-52.
58. Bitton A, Ratcliffe HL, Veillard JH, et al. Primary health care as a foundation for strengthening health systems in low- and middleincome countries. J Gen Intern Med 2017;32:566-71.

59. Balabanova D, Mckee M, Mills A. Good health at low costs- 25 years on, 2011.

60. Karan Aet al. Key indicators of morbidity, utilization and health expenditure - Tamil Nadu. Public Health Foundation of India, 2017.

61. Andrew M, Pritchett L, Woolcock M. Building state capability: evidence, analysis, action. Oxford: Oxford University Press, 2017.

62. Baru R, Acharya A, Acharya S, et al. Inequities in access to health services in India: caste, class and region. Econ Polit Wkly 2010;45:49-58

63. Chandra S, Bhattacharya S. Unqualified medical practitioners their illegal but indispensable role in primary healthcare. Econ Polit Wkly 2019;54:36-44.

64. Gautham M, Shyamprasad KM, Singh R, et al. Informal rural healthcare providers in North and south India. Health Policy Plan 2014;29(suppl 1):i20-9.

65. Vasan A, Anatole M, Mezzacappa C, et al. Baseline assessment of adult and adolescent primary care delivery in Rwanda: an opportunity for quality improvement. BMC Health Serv Res 2013;13.

66. Leslie HH, Spiegelman D, Zhou X, et al. Service readiness of health facilities in Bangladesh, Haiti, Kenya, Malawi, Namibia, Nepal, Rwanda, Senegal, Uganda and the United Republic of Tanzania. Bull World Health Organ 2017;95:738-48.

67. Ehiri JE, Oyo-Ita AE, Anyanwu EC, et al. Quality of child health services in primary health care facilities in south-east Nigeria. Child Care Health Dev 2005;31:181-91.

68. Kahabuka C, Moland KM, Kvåle G, et al. Unfulfilled expectations to services offered at primary health care facilities: experiences of caretakers of under-five children in rural Tanzania. BMC Health Serv Res 2012;14.

69. Government of Maharashtra. Status report of the Maharashtra state public health department. Directorate of health services, Mumbai, 2018. Available: https://arogya.maharashtra.gov.in/

70. Government of India. Bulletin of rural health statistics. New Delhi: Ministry of Health and Family Welfare, Government of India, 2017.

71. Duggal R, Dilip TR, Raymus P. Health and healthcare in Maharashtra. A status report. center for enquiry into health and allied themes, 2006. Available: https://hetv.org/pdf/maharashtra/ hhmbook.pdf

72. Government of India. National health profile issue 13. New Delhi: Ministry of Health and Family Welfare, Government of India, 2018.

73. Medical Council of India. Available: https://www.mciindia.org/ [Accessed 16 Feb 2019].

74. National Health Systems Resource Center. A review of existing regulatory mechanisms to address the shortage of doctors in rural, remote and underserved areas, 2016. Available: http://nhsrcindia. org/sites/default/files/Regulatory\%20study\%20report.pdf

75. Ambadekar N, Sharma K, Zodpey S, et al. Revisiting the district leve human resources for health architecture in department of public health in Maharashtra. Indian J Community Med 2015;40:75-8.

76. Ranjan A. Measuring equity as a dimension of progress towards universal health coverage (M.Phil thesis. Tata Institute of Social Sciences, 2017. 